\title{
Influence of annealing atmosphere on formation of electrically-active defects in rutile $\mathrm{TiO}_{2}$
}

Cite as: J. Appl. Phys. 123, 161572 (2018); https://doi.org/10.1063/1.5011136

Submitted: 30 October 2017 . Accepted: 13 December 2017 . Published Online: 23 January 2018

C. Zimmermann, J. Bonkerud, F. Herklotz, T. N. Sky, A. Hupfer, E. Monakhov, B. G. Svensson, and L. Vines

\section{ARTICLES YOU MAY BE INTERESTED IN}

Tutorial: Novel properties of defects in semiconductors revealed by their vibrational spectra Journal of Applied Physics 123, 161561 (2018); https://doi.org/10.1063/1.5011036

Tutorial: Junction spectroscopy techniques and deep-level defects in semiconductors Journal of Applied Physics 123, 161559 (2018); https://doi.org/10.1063/1.5011327

Iron and intrinsic deep level states in $\mathrm{Ga}_{2} \mathrm{O}_{3}$

Applied Physics Letters 112, 042104 (2018); https://doi.org/10.1063/1.5020134

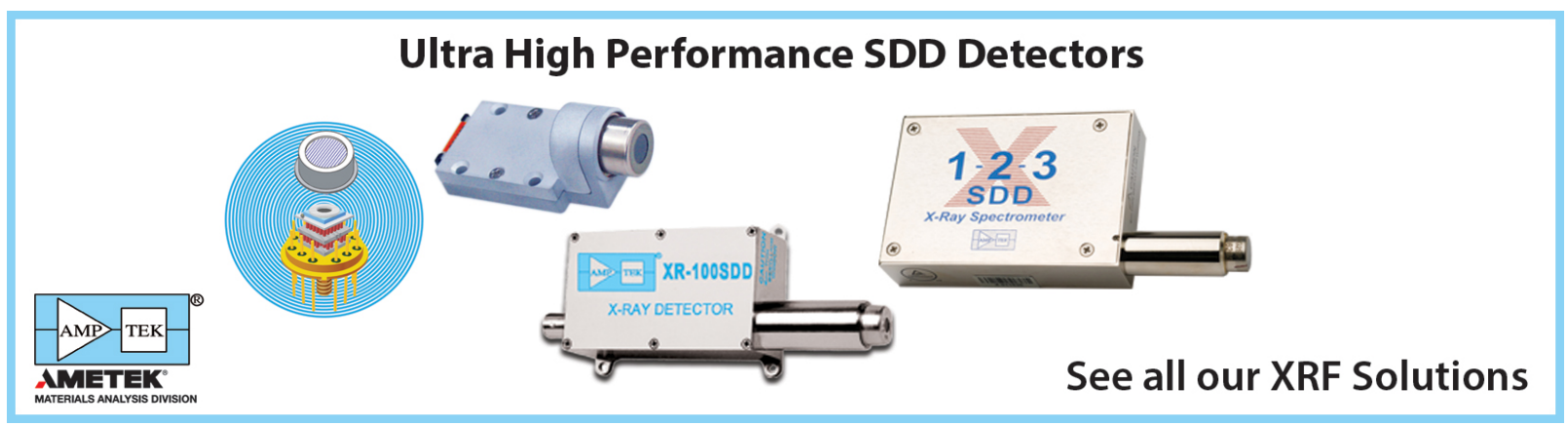




\title{
Influence of annealing atmosphere on formation of electrically-active defects in rutile $\mathrm{TiO}_{2}$
}

\author{
C. Zimmermann, ${ }^{1}$ J. Bonkerud, ${ }^{1}$ F. Herklotz, ${ }^{2}$ T. N. Sky, ${ }^{1}$ A. Hupfer, ${ }^{1}$ E. Monakhov, ${ }^{1}$ \\ B. G. Svensson, ${ }^{1}$ and L. Vines ${ }^{1}$ \\ ${ }^{1}$ Physics Department/Centre for Materials Science and Nanotechnology, University of Oslo, P.O. Box 1048, \\ Blindern, Oslo N-0316, Norway \\ ${ }^{2}$ Department of Physics, Freie Universität Berlin, 14195 Berlin, Germany
}

(Received 30 October 2017; accepted 13 December 2017; published online 23 January 2018)

\begin{abstract}
Electronic states in the upper part of the bandgap of reduced and/or hydrogenated $n$-type rutile $\mathrm{TiO}_{2}$ single crystals have been studied by means of thermal admittance and deep-level transient spectroscopy measurements. The studies were performed at sample temperatures between 28 and $300 \mathrm{~K}$. The results reveal limited charge carrier freeze-out even at $28 \mathrm{~K}$ and evidence the existence of dominant shallow donors with ionization energies below $25 \mathrm{meV}$. Interstitial atomic hydrogen is considered to be a major contributor to these shallow donors, substantiated by infrared absorption measurements. Three defect energy levels with positions of about $70 \mathrm{meV}, 95 \mathrm{meV}$, and $120 \mathrm{meV}$ below the conduction band edge occur in all the studied samples, irrespective of the sample production batch and the post-growth heat treatment used. The origin of these levels is discussed in terms of electron polarons, intrinsic point defects, and/or common residual impurities, where especially interstitial titanium atoms, oxygen vacancies, and complexes involving $\mathrm{Al}$ atoms appear as likely candidates. In contrast, no common deep-level defect, exhibiting a charge state transition in the $200-700 \mathrm{meV}$ range below the conduction band edge, is found in different samples. This may possibly indicate a strong influence on deep-level defects by the post-growth heat treatments employed. Published by AIP Publishing. https://doi.org/10.1063/1.5011136
\end{abstract}

\section{INTRODUCTION}

Titanium dioxide $\left(\mathrm{TiO}_{2}\right)$ in its rutile form has gained considerable attention for its photocatalytic properties ${ }^{1-3}$ or as part of solar cells. ${ }^{4,5}$ However, the bandgap of rutile $\mathrm{TiO}_{2}$ is approximately $3.2 \mathrm{eV},{ }^{6}$ which is too wide for utilizing the solar spectrum efficiently. ${ }^{6}$ Recently, reduced and/or hydrogenated $\mathrm{TiO}_{2}$ has received increasing interest because it exhibits stronger absorption in the visible/infrared wavelength regime than virgin rutile $\mathrm{TiO}_{2}{ }^{7,8}$ However, the understanding of intrinsic and impurity-related defects in this material is not fully developed to date, but it is of key importance in virtually all of its applications.

Reduced and/or hydrogenated rutile $\mathrm{TiO}_{2}$ exhibits $n$ type conductivity, ${ }^{9-13}$ but the nature of the main donor(s) is still under debate even after decades of research. The oxygen vacancy $\left(\mathrm{V}_{\mathrm{O}}\right)$, titanium interstitial $\left(\mathrm{Ti}_{\mathrm{i}}\right)$, and hydrogen on an interstitial site $\left(\mathrm{H}_{\mathrm{i}}\right)$ are considered to be potential sources of $n$-type doping. ${ }^{10,11,14-19}$ However, the properties of these donors remain elusive and controversial. The question which of these defects are dominant might furthermore strongly depend on the actual sample treatment. ${ }^{19}$ Importantly, hydrogen could be present in significant concentrations also in samples which were not intentionally hydrogenated. ${ }^{18}$

The identification of defects in rutile $\mathrm{TiO}_{2}$ is particularly challenging as the energy scheme of the defect levels may be influenced by polaronic effects. ${ }^{19-29}$ First, this makes the theoretical description of defects in rutile $\mathrm{TiO}_{2}$ exceptionally challenging. ${ }^{19,24}$ Second, polaronic effects can also lead to different defects having similar experimental signatures as electrons are trapped at similar $\mathrm{Ti}$ sites no matter which defect they actually originate from. ${ }^{19}$ Another consequence of the polaronic effects is that techniques which probe thermal or optical transition energies will yield significantly different values for the same defect. Hence, they cannot directly be used complementarily in identifying defects. . $^{19,20,23,24}$

This can, for example, be observed in the case of $\mathrm{H}_{\mathrm{i}}$ : Conductivity, transport, electron paramagnetic resonance, and infrared absorption measurements report on a shallow donor level with thermal transition energies of several $\mathrm{meV},{ }^{10,11,25,30-32}$ while absorption data indicate optical transition energies of around $1-2 \mathrm{eV} ., 28,32,33$

Another prominent example is $\mathrm{V}_{\mathrm{O}}$. Some experiments indicate that $\mathrm{V}_{\mathrm{O}}$ is a shallow donor in rutile $\mathrm{TiO}_{2}$, responsible for the $n$-type conductivity observed in samples annealed at low oxygen partial pressure, ${ }^{13,14,34}$ while other studies report $\mathrm{V}_{\mathrm{O}}$-related deep states. ${ }^{35,36}$ This controversy concerning $\mathrm{V}_{\mathrm{O}}$ is further complicated by the results of ab-initio calculations, as different studies strongly disagree on whether $\mathrm{V}_{\mathrm{O}}$ induces shallow effective mass-like states or deep donor levels. ${ }^{23,37-40}$

Space-charge spectroscopic techniques such as thermal admittance spectroscopy (TAS), ${ }^{41,42}$ deep-level transient spectroscopy (DLTS), ${ }^{43}$ and thermally stimulated current spectroscopy (TSC) ${ }^{44}$ probe thermal transition energies of electrically active defects. So far, only very few studies have been reported in the literature, where TAS, ${ }^{36}$ DLTS, ${ }^{35}$ and $\mathrm{TSC}^{45,46}$ are applied to gain insights into defect properties of rutile $\mathrm{TiO}_{2}$. Various defect levels between $130 \mathrm{meV}$ and $870 \mathrm{meV}$ below the conduction band edge have been reported; however, the identity of the associated defects remains unknown. 
The scarcity of reports on space-charge spectroscopy performed on rutile $\mathrm{TiO}_{2}$ is partially related to the difficulty in forming rectifying junctions. ${ }^{35,47}$ However, recent progress, see e.g., Ref. 48, shows promising results for Schottky contacts of sufficient quality to pursue TAS and DLTS studies on rutile $\mathrm{TiO}_{2}$.

In this work, we report on electrically active defects observed by TAS and DLTS measurements on rutile $\mathrm{TiO}_{2}$ single crystals subjected to different reducing and/or hydrogenating heat-treatments. Our results show that techniques such as TAS and DLTS are highly applicable for systematic studies of electrically active defects in non-stoichiometric rutile $\mathrm{TiO}_{2}$.

\section{EXPERIMENTAL}

The samples used in the present study were (001)-oriented rutile $\mathrm{TiO}_{2}$ single crystals grown by the float zone method and were purchased from MTI Corporation. The samples were acquired at different occasions and represent several different production batches. The as-received single crystals were colorless and semi-insulating, reflected by a resistivity of $>10^{7} \Omega \mathrm{cm}$. After cutting into $5 \times 5 \mathrm{~mm}^{2}$-sized samples, the crystals were cleaned in an ultrasonic bath with acetone, isopropanol, and deionized water for $5 \mathrm{~min}$ each. Afterwards, the samples were subjected to one of the three following heat treatments (annealings) using a tube furnace:

1. Annealing in forming gas flow $\left(\mathrm{N}_{2}+\mathrm{H}_{2}\right.$ with $\left[\mathrm{H}_{2}\right] /\left[\mathrm{N}_{2}\right]$ $\approx 1 / 9$, where the square brackets denote the concentration) at temperatures between $500^{\circ} \mathrm{C}$ and $600^{\circ} \mathrm{C}$ for 35-75 min. (forming gas annealing)

2. Annealing in closed ampules filled with $\mathrm{H}_{2}$ gas $(0.5$ bar at room temperature) for $20 \mathrm{~min}$ or $40 \mathrm{~min}$. The ampules were evacuated with a roughing pump before filling with $\mathrm{H}_{2}$. $\left(\mathrm{H}_{2}\right.$ gas annealing $)$

3. Annealing in $\mathrm{N}_{2}$ flow at temperatures between $980^{\circ} \mathrm{C}$ and $1250^{\circ} \mathrm{C}$ for $1.25-25 \mathrm{~h}$. ( $N_{2}$ gas annealing $)$

The samples were always put into the furnace when the desired annealing temperature $T_{\text {anneal }}$ was reached. After the heat treatment, the samples were cooled-down without force in the cold furnace zone while maintaining the gas flow. Subsequently, the annealed crystals were cleaned again using the afore-mentioned procedure and further boiled in $\mathrm{H}_{2} \mathrm{O}_{2}$ (40\%) for 1-3 min. This treatment is commonly used for the preparation of Schottky diodes on $\mathrm{ZnO}$ and has proven to lead to highly rectifying diodes. ${ }^{49}$

Between 10 and $15 \mathrm{Pd}$ contacts with a thickness in the range of $\sim 150-200 \mathrm{~nm}$ were deposited onto the samples via electron beam evaporation, using a Si shadow mask with pad areas of $0.7 \times 10^{-3}$ to $4.2 \times 10^{-3} \mathrm{~cm}^{2}$. Eutectic InGa was used as Ohmic back contact.

Secondary ion mass spectrometry (SIMS) measurements were performed using a Cameca IMS $7 \mathrm{f}$ instrument with a primary beam of $10 \mathrm{keV} \mathrm{O}+$ ions. Rutile $\mathrm{TiO}_{2}$ samples implanted with $\mathrm{Cr}, \mathrm{Al}$, or $\mathrm{Si}$ were used as references to obtain absolute concentration values. For other residual elements, relative concentrations were determined. A constant erosion rate was assumed for depth-calibration, where the crater depths were measured using a surface Stylus Profilometer.

Fourier transform infrared (FTIR) absorbance spectra were recorded with a Bruker IFS125 HR spectrometer equipped with a globar or tungsten light source, a $\mathrm{KBr}$ or $\mathrm{CaF}_{2}$ beam splitter, and an InSb detector. Measurements were performed with a spectral resolution of $0.5 \mathrm{~cm}^{-1}$ and at a sample temperature of $27 \mathrm{~K}$. Unpolarized light was used with the wave vector, $\vec{k}$, directed perpendicular to the $\vec{c}$-axis of the samples.

The current-voltage (IV) and capacitance-voltage (CV) measurements were carried out under dark conditions at room temperature using a Keithley 6487 unit and an Agilent 4284A LCR meter, respectively.

DLTS was conducted using a refined version of the setup described elsewhere. ${ }^{50}$ In short, the setup utilizes a Boonton 7200 capacitance meter and a closed-cycle He cryostat. During measurements, reverse bias voltages between $-4 \mathrm{~V}$ and $-3 \mathrm{~V}$ were applied. Filling pulses with an amplitude of $2 \mathrm{~V}$ to $4 \mathrm{~V}$ and a duration of $50 \mathrm{~ms}$ were employed. The DLTS signal was extracted from the acquired capacitanceversus-time transients using a lock-in weighting function ${ }^{51}$ with six different rate windows in the range of $(20 \mathrm{~ms})^{-1}$ to $(640 \mathrm{~ms})^{-1}$. A delay time of $5 \mathrm{~ms}$ and a temperature resolution of $1 \mathrm{~K}$ were used. Measurements were performed both during heat-up and cool-down.

TAS measurements were conducted with a temperature resolution of $1 \mathrm{~K}$ during heat-up and cool-down using an Agilent $4284 \mathrm{~A}$ LCR meter at probe frequencies $f_{\text {meas }}$ between $10 \mathrm{kHz}$ and $1 \mathrm{MHz}$. Further details about the setup used can be found in Ref. 52.

\section{RESULTS}

SIMS measurements were performed in order to monitor selected relevant impurities in the heat-treated samples. $\mathrm{Cr}$ and $\mathrm{Li}, \mathrm{Al}$, and $\mathrm{Si}$ are present in significant concentrations, where the relative concentrations vary by at least an order of magnitude between different samples for $\mathrm{Cr}\left(10^{16}-10^{17} \mathrm{~cm}^{-3}\right), \mathrm{Al}$ $\left(10^{16}-10^{17} \mathrm{~cm}^{-3}\right)$, and $\mathrm{Li}\left(\leq 10^{16} \mathrm{~cm}^{-3}\right)$, whilst lower variations are found for $\mathrm{Si}\left(10^{17} \mathrm{~cm}^{-3}\right)$.

FTIR measurements were undertaken to determine the concentration of interstitial hydrogen $\left(\mathrm{H}_{\mathrm{i}}\right)$ from its $\mathrm{O}-\mathrm{H}$ vibrational mode at $\sim 3290 \mathrm{~cm}^{-1}$. 30,53 The as-received $\mathrm{TiO}_{2}$ samples reveal a $\mathrm{H}_{\mathrm{i}}$ concentration in the range of $1-3 \times 10^{16} \mathrm{~cm}^{-3}$. The heat treatments result in an increase of $\left[\mathrm{H}_{\mathrm{i}}\right]$. For the $\mathrm{N}_{2}$ gas annealed samples, $\left[\mathrm{H}_{\mathrm{i}}\right]$ increases to about $5 \times 10^{17} \mathrm{~cm}^{-3}$. Substantially, more $\mathrm{H}_{\mathrm{i}}$ is observed in the case of annealing in $\mathrm{H}_{2}$ gas or forming gas. In both cases, precise quantitative measurements are prevented because of the high $\left[\mathrm{H}_{\mathrm{i}}\right]$, leading to saturation of the O-H vibrational mode in the FTIR absorbance spectra.

Generally, different $\mathrm{Pd} / \mathrm{TiO}_{2} / \mathrm{InGa}$ junctions on the same $\mathrm{TiO}_{2}$ sample display different IV characteristics, especially in terms of rectification. This indicates an inhomogeneity of the as-received samples unveiled by the applied annealing procedure. For some diodes, rectifications of up to six orders of magnitude in current can be found when the applied voltage $V$ is varied between $-4 \mathrm{~V}$ and $4 \mathrm{~V}$. In Fig. 1, examples of 


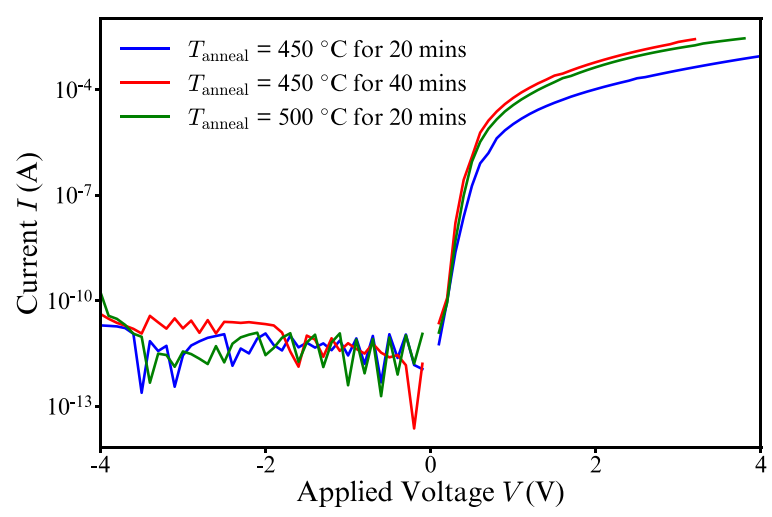

FIG. 1. IV curves of Pd Schottky contacts on $\mathrm{H}_{2}$ gas annealed $\mathrm{TiO}_{2}$ single crystals.

such IV curves are shown for $\mathrm{H}_{2}$ gas annealed samples. In general, similar results are obtained independently of the specific annealing procedure used.

In Fig. 2, the results of CV measurements using different probe frequencies $(4 \mathrm{kHz}-1 \mathrm{MHz})$ are shown for two $\mathrm{Pd} /$ $\mathrm{TiO}_{2} /$ InGa junctions by depicting $1 / C^{2}$ versus $V$. Two equivalent circuits consisting of only one resistance and capacitance were assumed to deduce the capacitance of the junctions (see also the inset of Fig. 2): (i) Capacitance $C_{\mathrm{P}}$ parallel to a resistance $R_{\mathrm{P}}$ (solid lines and left inset) and (ii) Capacitance $C_{\mathrm{S}}$ and a resistance $R_{\mathrm{S}}$ in series (dashed lines and right inset).

According to the depletion approximation, the depletion layer capacitance $C_{\mathrm{d}}$ of a Schottky junction on an $n$-type semiconductor is given by ${ }^{54}$

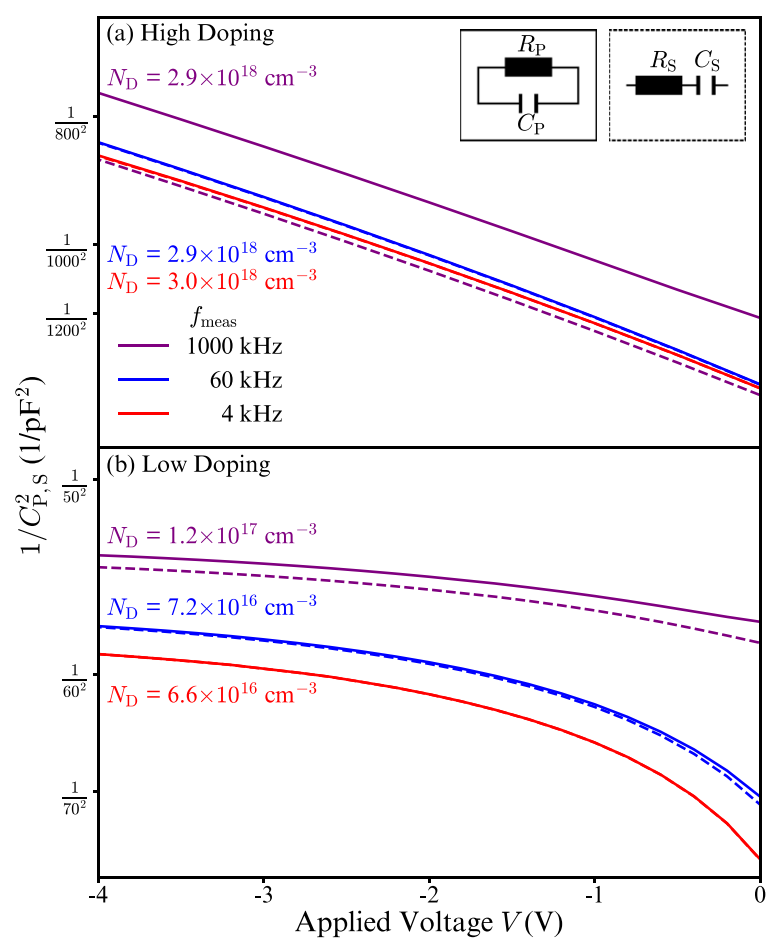

FIG. 2. Frequency-dependent $1 / C_{\mathrm{P}, \mathrm{S}}^{2}-V$ plots for Pd Schottky contacts on forming gas annealed $\mathrm{TiO}_{2}$ crystals. An equivalent circuit with the depletion layer capacitance $C_{\mathrm{d}}$ either in parallel (solid lines and left inset) or in series (dashed lines and right inset) with a resistance has been assumed.

$$
C_{\mathrm{d}}=\sqrt{\frac{A^{2} \epsilon_{0} \epsilon_{\mathrm{r}} e N_{\mathrm{D}}}{2\left(V_{\mathrm{bi}}+V_{\mathrm{bias}}\right)}} .
$$

Here, $A$ denotes the junction area, $\epsilon_{0}$ the vacuum permittivity, $\epsilon_{\mathrm{r}}$ the static dielectric constant, $e$ the elementary charge, $N_{\mathrm{D}}$ the donor concentration, $V_{\mathrm{bi}}$ the built-in voltage, and $V_{\text {bias }}$ the applied bias voltage. A static dielectric constant $\epsilon_{\mathrm{r}}$ of 100 was assumed. ${ }^{10-12,55,56}$ For a uniform donor concentration, one expects a straight line for $1 / C_{\mathrm{d}}^{2}$ versus $V,{ }^{54}$ which holds reasonably well for the highly doped sample in Fig. 2(a). From the slope of the curves, we obtain a donor concentration $N_{\mathrm{D}}$ of about $3 \times 10^{18} \mathrm{~cm}^{-3}$. For high reverse bias voltages and the highest probe frequency employed $(1 \mathrm{MHz})$, a linear behavior is also observed for the low-doped sample [see Fig. 2(b)]. From the corresponding slope, a donor concentration $N_{\mathrm{D}}$ of about $1 \times 10^{17} \mathrm{~cm}^{-3}$ is obtained. For low reverse bias voltages and especially low probe frequencies, pronounced deviations from a linear dependence occur as will be commented on in the discussion Sec. IV A.

\section{A. Thermal admittance spectroscopy}

In TAS, the capacitance $C$ and conductance $G$ of a rectifying junction are determined as a function of sample temperature $T$ and probe frequency $f_{\text {meas }}^{41,42}$ by assuming an appropriate equivalent circuit for the junction. ${ }^{57}$ Here, a series circuit was assumed and the measured capacitance is denoted as $C_{\mathrm{S}}$ for series capacitance [see also the right inset of Fig. 2(a)].

When crossed by the Fermi level, shallow defect levels being present in the junction give rise to inflection points $T_{\text {inf }}$ in the $C-T$ spectra $^{41,42,58}$ and can be used to determine the activation energy (enthalpy) $E_{\mathrm{A}}=E_{\mathrm{C}}-E_{\mathrm{D}}\left(E_{\mathrm{C}}=\right.$ conduction band edge and $E_{\mathrm{D}}=$ defect level position) of shallow states using $^{42,54}$

$$
\frac{2 \pi f_{\text {meas }}}{T_{\text {inf }}^{2}} \sim \exp \left(-\frac{E_{\mathrm{A}}}{k_{\mathrm{b}} T_{\mathrm{inf}}}\right),
$$

where $k_{\mathrm{b}}$ denotes the Boltzmann constant.

Figure 3 shows representative TAS spectra obtained on four different $\mathrm{Pd} / \mathrm{TiO}_{2} / \mathrm{InGa}$ junctions. The corresponding $\mathrm{TiO}_{2}$ samples were forming gas annealed (a) and (b), $\mathrm{H}_{2}$ gas annealed (c), and $\mathrm{N}_{2}$ gas annealed (d). Several inflection points in the $C_{\mathrm{S}}-T$ plots are revealed, which correspond to electron states being present in $\mathrm{TiO}_{2}$. The values of $T_{\text {inf }}$ to be used in Eq. (2) were extracted from the local maxima positions in the derivative spectra $\mathrm{d} C_{\mathrm{S}} / \mathrm{d} T^{58}$ [see the example in the inset of Fig. 3(b)].

All the investigated forming gas annealed samples [see Figs. 3(a) and 3(b)] show the electron levels labeled $D_{2, \mathrm{FG}}$ and $D_{3, \mathrm{FG}}$. $D_{4, \mathrm{FG}}$ is only present in some samples in sufficient concentrations to be detected by TAS. The levels labeled $D_{1, \mathrm{H}}, D_{2, \mathrm{H}}$, and $D_{3, \mathrm{H}}$ are seen for all the investigated samples annealed in $\mathrm{H}_{2}$ gas [see Fig. 3(c)]. For all the investigated samples annealed in $\mathrm{N}_{2}$ gas, the levels $D_{2, \mathrm{~N}}$ and $D_{3, \mathrm{~N}}$ are observed, while $D_{4, \mathrm{~N}}$ is only detected in a few samples. $D_{1, \mathrm{FG}}, D_{1, \mathrm{H}}$, and $D_{1, \mathrm{~N}}$ can only be resolved at very low temperatures. 

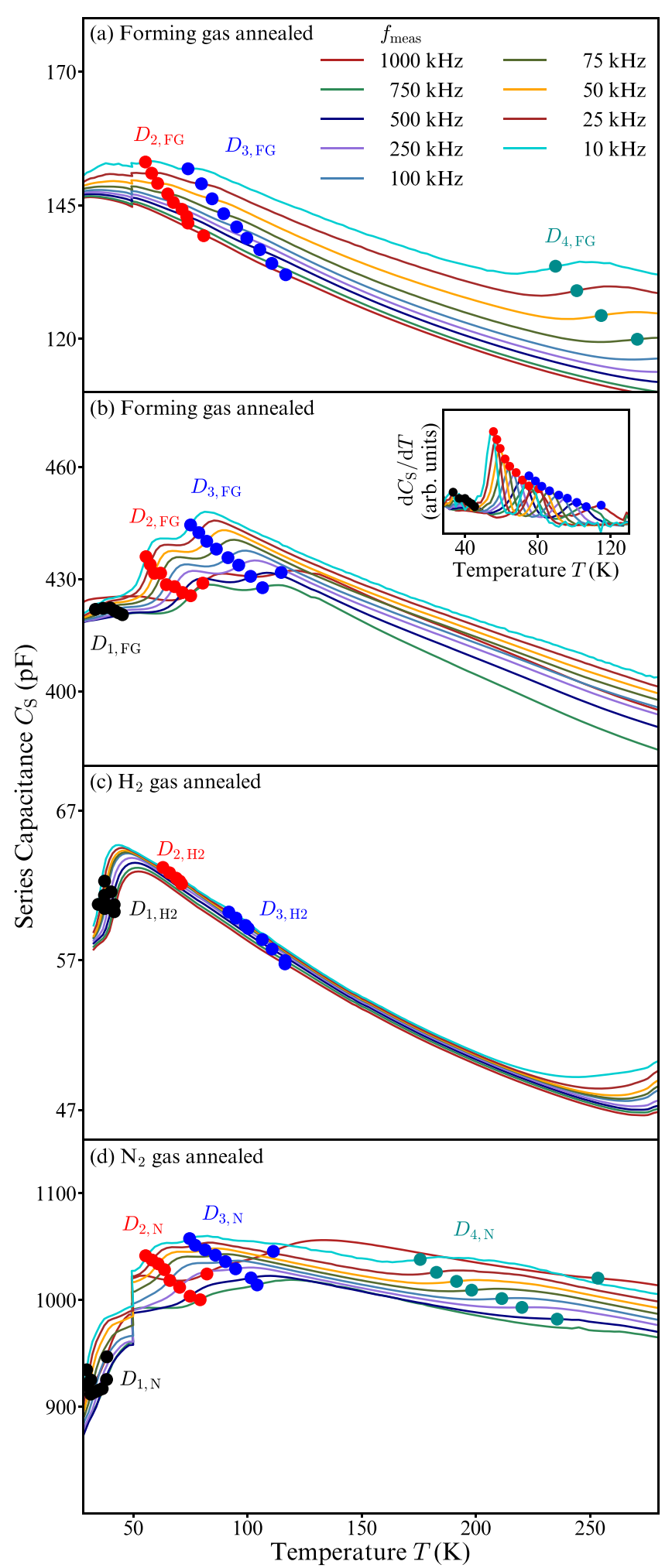

FIG. 3. $C_{\mathrm{S}}-T$ plots for four different $\mathrm{Pd} / \mathrm{TiO}_{2} / \mathrm{InGa}$ junctions. The inset in (b) shows $\mathrm{d} C_{\mathrm{S}} / \mathrm{d} T$ over $T$, which was used to determine $T_{\text {inf }}$ [see Eq. (2)].

By comparing the value pairs $\left(T_{\text {inf }}, f_{\text {meas }}\right)$ for the electron levels observed in samples subjected to different heattreatments, it is found that $D_{2, \mathrm{FG}}$ and $D_{2, \mathrm{~N}}$, as well as $D_{3, \mathrm{FG}}$ and $D_{3, \mathrm{~N}}$, respectively, can arise from the same electron levels.

Figure 4 displays Arrhenius plots obtained from the TAS spectra shown in Fig. 3 according to Eq. (2). Linear least-

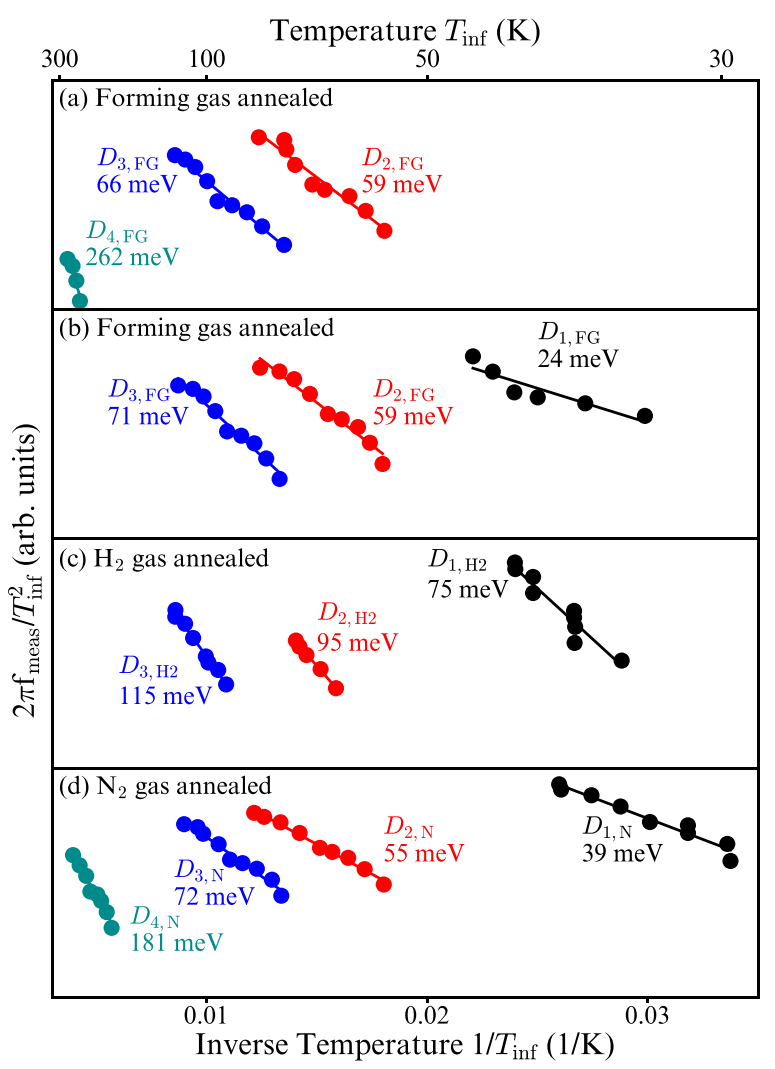

FIG. 4. Arrhenius plots derived from the $C_{\mathrm{S}}-T$ curves shown in Fig. 3 using Eq. (2).

squares fits, represented by solid lines in Fig. 4, have been used to determine $E_{\mathrm{A}}$. In Table I, the obtained activation energy values of the observed electron levels are summarized.

\section{B. Deep-level transient spectroscopy}

DLTS was used to probe deep electron traps in heattreated $\mathrm{TiO}_{2}$ samples. The trap concentration $N_{\mathrm{T}}$ was deduced assuming a uniform and sufficiently low $\left(\leq 0.1 N_{\mathrm{D}}\right)$ defect distribution, where ${ }^{43,54}$

$$
N_{\mathrm{T}}=2 \frac{\Delta C}{C_{\mathrm{rb}}} N_{\mathrm{D}} .
$$

Here, $\Delta C$ is determined from the measured capacitance transients, ${ }^{43,51,54}$ while $C_{\mathrm{rb}}$ is the capacitance measured at the

TABLE I. Overview of thermal activation energies $E_{\mathrm{A}}$ determined by TAS on $\mathrm{Pd} / \mathrm{TiO}_{2} / \mathrm{InGa}$ junctions. Subscript FG: forming gas annealing, $\mathrm{N}: \mathrm{N}_{2}$ gas annealing, and $\mathrm{H} 2: \mathrm{H}_{2}$ gas annealing. The intervals stated take into account the fitting errors and the spread across the surface of the samples measured.

\begin{tabular}{|c|c|c|c|c|c|}
\hline \multicolumn{2}{|c|}{ Forming gas annealed } & \multicolumn{2}{|c|}{$\mathrm{H}_{2}$ gas annealed } & \multicolumn{2}{|c|}{$\mathrm{N}_{2}$ gas annealed } \\
\hline $\begin{array}{l}\text { Defect } \\
\text { level }\end{array}$ & $\begin{array}{c}E_{\mathrm{A}} \\
(\mathrm{meV})\end{array}$ & $\begin{array}{c}\text { Defect } \\
\text { level }\end{array}$ & $\begin{array}{c}E_{\mathrm{A}} \\
(\mathrm{meV})\end{array}$ & $\begin{array}{c}\text { Defect } \\
\text { level }\end{array}$ & $\begin{array}{c}E_{\mathrm{A}} \\
(\mathrm{meV})\end{array}$ \\
\hline$D_{1, \mathrm{FG}}$ & {$[19,29]$} & $D_{1, \mathrm{H} 2}$ & {$[67,84]$} & $D_{1, \mathrm{~N}}$ & {$[35,42]$} \\
\hline$D_{2, \mathrm{FG}}$ & {$[54,65]$} & $D_{2, \mathrm{H} 2}$ & {$[92,98]$} & $D_{2, \mathrm{~N}}$ & {$[53,57]$} \\
\hline$D_{3, \mathrm{FG}}$ & {$[62,75]$} & & & $D_{4, \mathrm{~N}}$ & {$[169,192]$} \\
\hline$D_{4, \mathrm{FG}}$ & {$[206,318]$} & & & & \\
\hline
\end{tabular}


quiescent reverse bias voltage. $N_{\mathrm{D}}$ is derived from $\mathrm{CV}$ measurements. ${ }^{54}$

For each DLTS rate window, the peak in $\Delta C$ occurs at a different $T_{\max }$. Using the following relation for the electron emission rate $e_{\mathrm{n}}$ at the DLTS peak maximum ${ }^{54}$

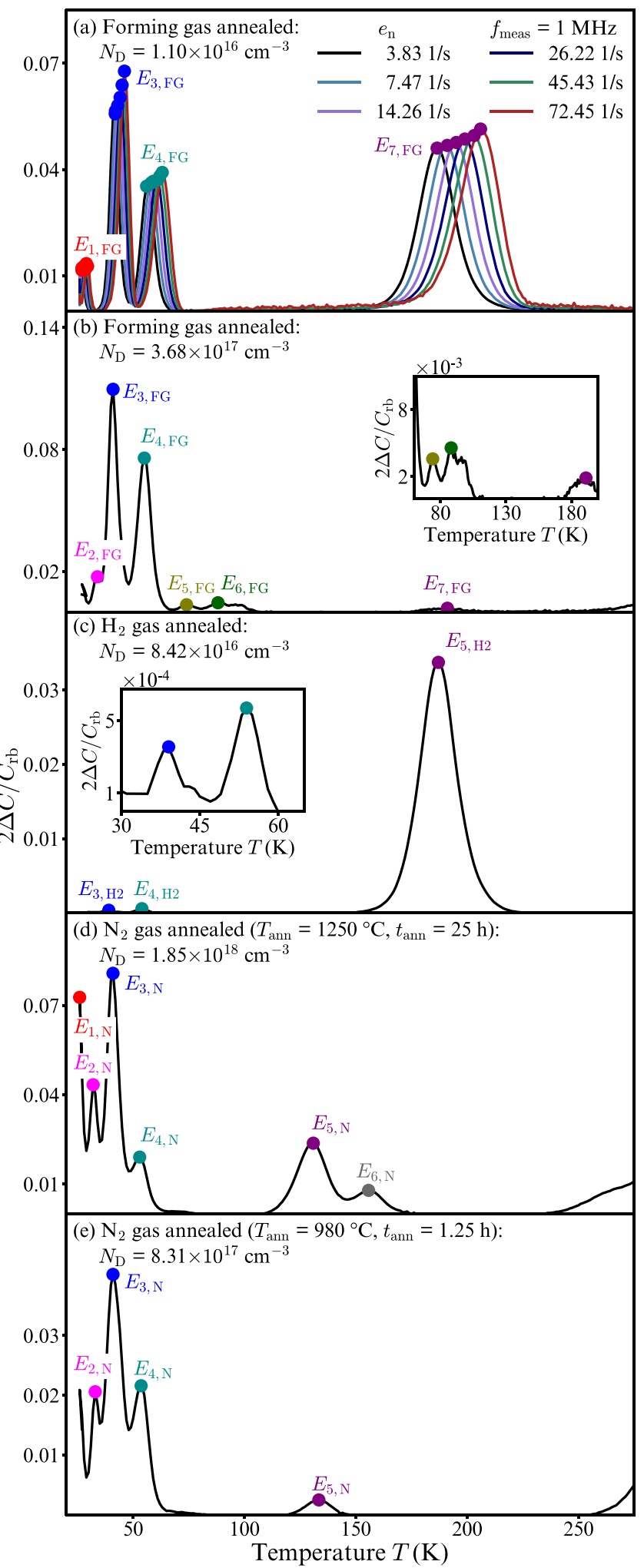

FIG. 5. DLTS results for five different $\mathrm{Pd} / \mathrm{TiO}_{2} / \mathrm{InGa}$ junctions. In (a), results for the six rate windows used for obtaining Arrhenius plots are shown. In (b)-(e), only the results for the longest rate window are displayed $\left(e_{\mathrm{n}}=3.83 \mathrm{~s}^{-1}\right.$ at the peak maximum).

$$
\frac{e_{\mathrm{n}}}{T_{\max }^{2}}=\beta \sigma_{\mathrm{a}} \exp \left(-\frac{E_{\mathrm{A}}}{k_{\mathrm{b}} T_{\max }}\right),
$$

the apparent capture cross-section $\sigma_{\mathrm{a}}$ and the thermal activation energy $E_{\mathrm{A}}$ for the deep-level defect can be determined. $\beta$ is a material-specific constant and is given by ${ }^{43,54}$

$$
\beta=2 \sqrt{3}\left(\frac{2 \pi}{h^{2}}\right)^{3 / 2} k_{\mathrm{b}}^{2} m_{\mathrm{e}}^{*}
$$

Here, $m_{\mathrm{e}}^{*}$ denotes the effective electron mass in $\mathrm{TiO}_{2}$, while $h$ is the Planck constant. There is quite a spread in values reported for $m_{\mathrm{e}}^{*} \cdot{ }^{11,34,59-64}$ In this study, a value of ten-times the free electron mass $m_{\mathrm{e}}$ is assumed.

Figure 5 displays exemplary DLTS spectra measured on $\mathrm{Pd} / \mathrm{TiO}_{2} / \mathrm{InGa}$ junctions. Figures 5(a) and 5(b) show the results for forming gas annealed samples, where seven different defect levels are observed. The levels labeled $E_{3, \mathrm{FG}}$ and $E_{4, \mathrm{FG}}$ are present in all samples irrespective of the annealing conditions used (duration or temperature) and the specific production batch from which the $\mathrm{TiO}_{2}$ single crystals originated. $E_{1, \mathrm{FG}}$ appears at very low temperatures and was not resolved for all the measurements shown here. The levels $E_{2, \mathrm{FG}}, E_{5, \mathrm{FG}}, E_{6, \mathrm{FG}}$, and $E_{7, \mathrm{FG}}$ occur occasionally and were not observed in all the investigated samples.

In Fig. 5(c), a DLTS spectrum of a $\mathrm{H}_{2}$ gas annealed sample is shown. Different annealing durations and/or temperatures lead to qualitatively similar DLTS spectra with similar levels being present and $E_{5, \mathrm{H} 2}$ as the dominant one. All the investigated samples originated from the same production batch.

Figures 5(d) and 5(e) show DLTS results for the $\mathrm{N}_{2}$ gas annealed samples. The samples originated from the same production batch but were subjected to different annealing durations and temperatures. The levels $E_{2, \mathrm{~N}}, E_{3, \mathrm{~N}}, E_{4, \mathrm{~N}}$, and $E_{5, \mathrm{~N}}$ are observed in all the samples, whereas $E_{6, \mathrm{~N}}$ is only present in samples annealed at high temperatures and for long durations. The level $E_{1, \mathrm{~N}}$ is very shallow and can only be resolved fully at low temperatures using short rate windows.

When comparing the $\left(T_{\max }, e_{\mathrm{n}}\right)$ pairs for the observed defect levels across samples subjected to different heattreatments, it can be found that the following defect levels may have the same origin: $E_{2, \mathrm{~N}}$ and $E_{2, \mathrm{FG}}, E_{3, \mathrm{~N}}, E_{3, \mathrm{FG}}$, and $E_{3, \mathrm{H} 2}$, and $E_{4, \mathrm{FG}}, E_{4, \mathrm{~N}}$, and $E_{4, \mathrm{H} 2}$.

In Table II, an overview of the observed defect levels and their activation energy values, as well as apparent capture cross sections, is given. Due to the ambiguity concerning the value of the effective electron mass $m_{\mathrm{e}}^{*}$, only orders of magnitude values are stated for $\sigma_{\mathrm{a}}$.

\section{DISCUSSION}

\section{A. Experimental remarks}

Generally, the $\mathrm{Pd} / \mathrm{TiO}_{2} / \mathrm{InGa}$ junctions display high rectification (see Fig. 1) as required for accurate space-charge spectroscopy measurements. In the case of highly doped samples, the $\mathrm{CV}$ characteristics resemble those expected for a depletion layer capacitance under uniform doping [see the linear $1 / C^{2}-V$ dependency in Fig. 2(a)]. However, 
TABLE II. Overview of thermal activation energies $E_{\mathrm{A}}$ and apparent capture cross sections $\sigma_{\mathrm{a}}$ determined using DLTS on Pd/TiO $/$ /nGa junctions. Subscript FG: forming gas annealing, $\mathrm{N}: \mathrm{N}_{2}$ gas annealing, and $\mathrm{H} 2: \mathrm{H}_{2}$ gas annealing. The intervals stated for $E_{\mathrm{A}}$ take into account fitting errors and the scatter between the measured samples. The values stated for $\sigma_{\mathrm{a}}$ take only into account the scatter across the surface of the samples because of the large uncertainty.

\begin{tabular}{|c|c|c|c|c|c|c|c|c|}
\hline \multicolumn{3}{|c|}{ Forming gas annealed } & \multicolumn{3}{|c|}{$\mathrm{H}_{2}$ gas annealed } & \multicolumn{3}{|c|}{$\mathrm{N}_{2}$ gas annealed } \\
\hline Defect level & $E_{\mathrm{A}}(\mathrm{meV})$ & $\sigma_{\mathrm{a}}\left(\mathrm{cm}^{2}\right)$ & Defect level & $E_{\mathrm{A}}(\mathrm{meV})$ & $\sigma_{\mathrm{a}}\left(\mathrm{cm}^{2}\right)$ & Defect level & $E_{\mathrm{A}}(\mathrm{meV})$ & $\sigma_{\mathrm{a}}\left(\mathrm{cm}^{2}\right)$ \\
\hline$E_{1, \mathrm{FG}}$ & {$[57,76]$} & $10^{-13}$ & $E_{1, \mathrm{H} 2}$ & {$[49,96]$} & $10^{-11}$ & $E_{2, \mathrm{~N}}$ & {$[63,93]$} & {$\left[10^{-15}, 10^{-12}\right]$} \\
\hline$E_{2, \mathrm{FG}}$ & {$[69,96]$} & {$\left[10^{-14}, 10^{-12}\right]$} & $E_{3, \mathrm{H} 2}$ & {$[81,104]$} & $10^{-14}$ & $E_{1, \mathrm{~N}}$ & {$[82,99]$} & $10^{-12}$ \\
\hline$E_{3, \mathrm{FG}}$ & {$[87,111]$} & {$\left[10^{-15}, 10^{-13}\right]$} & $E_{4, \mathrm{H} 2}$ & {$[92,144]$} & {$\left[10^{-16}, 10^{-14}\right]$} & $E_{3, \mathrm{~N}}$ & {$[86,109]$} & {$\left[10^{-15}, 10^{-13}\right]$} \\
\hline$E_{6, \mathrm{FG}}$ & {$[104,114]$} & $10^{-20}$ & $E_{5, \mathrm{H} 2}$ & {$[446,471]$} & {$\left[10^{-15}, 10^{-14}\right]$} & $E_{4, \mathrm{~N}}$ & {$[110,123]$} & $10^{-15}$ \\
\hline$E_{4, \mathrm{FG}}$ & {$[111,132]$} & {$\left[10^{-15}, 10^{-14}\right]$} & & & & $E_{5, \mathrm{~N}}$ & {$[273,313]$} & {$\left[10^{-16}, 10^{-15}\right]$} \\
\hline$E_{5, \mathrm{FG}}$ & {$[204,218]$} & $10^{-12}$ & & & & $E_{6, \mathrm{~N}}$ & {$[365,395]$} & {$\left[10^{-15}, 10^{-14}\right]$} \\
\hline$E_{7, \mathrm{FG}}$ & {$[424,630]$} & {$\left[10^{-14}, 10^{-13}\right]$} & & & & & & \\
\hline
\end{tabular}

deviations from this behavior are evident for low doped samples [see Fig. 2(b)]. These deviations can be caused by a non-uniform doping concentration, a highly compensated interfacial layer being present between the metal contact(s) and $\mathrm{TiO}_{2},{ }^{47,65-67}$ a high density of deep defect levels not responding fully to the probe frequency, ${ }^{68}$ or high series resistance. $^{69,70}$

Our set of data indicates that several of these causes contribute to the recorded CV characteristics, especially high series resistance and the presence of a highly compensated interfacial layer. We found that their relative contribution depends on the sample and its particular treatment. By using comparatively small contact areas, the effect of the high series resistance can be minimized, ${ }^{69,70}$ and a detailed analysis of the CV characteristics and barrier heights of the Schottky junctions used in this work can be found in Ref. 48 .

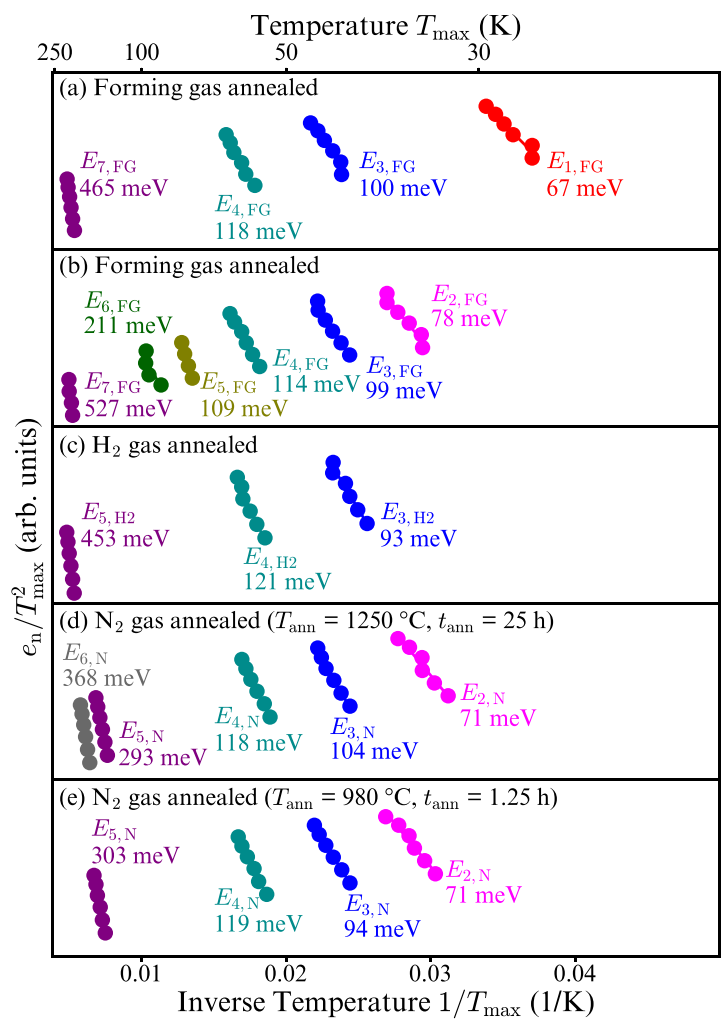

FIG. 6. Arrhenius plots according to Eq. (4) derived from the DLTS measurements shown in Fig. 5.
The interpretation of TAS and DLTS data is facilitated by uniform net carrier concentration versus depth profiles acquired at high measurement frequencies $(\geq 10 \mathrm{kHz})$. Indeed, this was confirmed for all the samples presented here prior to TAS and/or DLTS measurements. The validity of the TAS and DLTS analysis is furthermore corroborated by the applicability of Eqs. (2) and (4). For essentially all the observed defect levels, an Arrhenius dependence holds for the extracted electron emission rates. The exception is the shallow level $D_{1, \mathrm{FG}}$, which is affected by charge carrier freeze-out.

\section{B. Origin of the observed defect levels}

The data in Figs. 3-6 reveal the presence of some rather prominent shallow electron traps $\left(E_{\mathrm{A}} \leq 130 \mathrm{meV}\right)$ and that charge carrier-freeze out is limited even at $28 \mathrm{~K}$. Irrespective of the sample production batch and the post-growth heat treatment employed, three particular levels always occur. They exhibit similar electron emission rates as a function of temperature in each sample with $E_{\mathrm{A}} \approx 70 \mathrm{meV}\left(D_{3, \mathrm{FG}}, E_{2, \mathrm{FG}}\right.$, $D_{1, \mathrm{H} 2}, D_{2, \mathrm{~N}}$, and $\left.E_{2, \mathrm{~N}}\right), E_{\mathrm{A}} \approx 95 \mathrm{meV}\left(E_{3, \mathrm{FG}}, D_{2, \mathrm{H} 2}, E_{3, \mathrm{H} 2}\right.$, and $\left.E_{2, \mathrm{~N}}\right)$, and $E_{\mathrm{A}} \approx 120 \mathrm{meV}\left(E_{4, \mathrm{FG}}, D_{3, \mathrm{H} 2}\right.$, and $\left.E_{4, \mathrm{~N}}\right)$, respectively. This implies that these levels arise from intrinsic defects or defects involving omnipresent residual impurities. Generally, the absolute concentrations of defect levels in $\mathrm{TiO}_{2}$ are difficult to determine with a high degree of accuracy because of the uncertainty in the dielectric constant (permittivity). ${ }^{10-12,55,56}$ However, by assuming $\epsilon_{\mathrm{r}}=100$ (as for the CV data), one arrives at values of $10^{15}-10^{17} \mathrm{~cm}^{-3}$ for most of the levels in Fig. 5.

Polaronic effects are strong in rutile $\mathrm{TiO}_{2}$ and may be responsible for some of the observed levels via self-trapping of electrons on Ti sites. For instance, Frederikse ${ }^{61}$ and Deák et al., ${ }^{24}$ as well as Janotti et al., ${ }^{23}$ have reported experimental and theoretical indications, respectively, of such electron states with $E_{\mathrm{A}}$ below $150 \mathrm{meV}$. Other prevalent intrinsic candidates anticipated in reduced rutile $\mathrm{TiO}_{2}$ are the donor-like $\mathrm{Ti}_{\mathrm{i}}$ and $\mathrm{V}_{\mathrm{O}}$ centers. ${ }^{6,16,17,19}$ However, reports on the $E_{\mathrm{A}}$ values for these two centers are scarce in the literature. Brandão et al. ${ }^{14}$ suggested $E_{\mathrm{A}} \approx 2.8 \mathrm{meV}$ for a $\mathrm{V}_{\mathrm{O}}$ donor-state based on electron paramagnetic resonance measurements, which is considerably lower than the thermal activation energy of our three "general" levels. On the other hand, rather recent 
density functional theory (DFT) calculations by Janotti et $a l^{23}$ predict single and double donor states of $\mathrm{V}_{\mathrm{O}}$ with $E_{\mathrm{A}}$ equal to about $100 \mathrm{meV}$ and $140 \mathrm{meV}$, respectively, for a configuration where the donor electrons are rather localized at neighboring $\mathrm{Ti}$ atoms $\left(\mathrm{V}_{\mathrm{O}}^{+2}+2 \mathrm{Ti}^{+3}\right)$. Hence, $\mathrm{V}_{\mathrm{O}}$ cannot be excluded as the origin of our $95 \mathrm{meV}$ and $120 \mathrm{meV}$ levels. Furthermore, Deák et al. ${ }^{24}$ computed $E_{\mathrm{A}} \approx 100 \mathrm{meV}$ and $\approx 1300 \mathrm{meV}$ for the single and double donor states, respectively, of a $\mathrm{V}_{\mathrm{O}}$ configuration where the electrons are localized at the $\mathrm{V}_{\mathrm{O}}$ site. Mattioli et al. ${ }^{37}$ conducted similar calculations as in Ref. 24 but found a substantially lower $E_{\mathrm{A}}$ value of about $300 \mathrm{meV}$ for the double donor state. For thermally induced charge state transitions of $\mathrm{Ti}_{\mathrm{i}}$ in rutile $\mathrm{TiO}_{2}$, Hubbard-U corrected DFT data by Mattioli et al. ${ }^{37}$ suggest that the single and double donor levels are resonant with the conduction band, whilst the triple and quadruple ones are located in the bandgap at $\approx 70 \mathrm{meV}$ and $400 \mathrm{meV}$ below the conduction band edge. Thus, $\mathrm{Ti}_{\mathrm{i}}$ may be an intrinsic candidate for the common level observed at $70 \mathrm{meV}$ in our samples.

Main residual impurities found in all the investigated samples are $\mathrm{H}, \mathrm{Li}, \mathrm{Al}, \mathrm{Si}$, and $\mathrm{Cr}$ according to FTIR and SIMS measurements. Li displays a concentration below $10^{16} \mathrm{~cm}^{-3}$, and the three latter ones exhibit concentrations between $10^{16}$ and $10^{17} \mathrm{~cm}^{-3}$. The $\mathrm{H}$ content is estimated to increase from the $10^{16} \mathrm{~cm}^{-3}$ range in the as-received samples to above $10^{18} \mathrm{~cm}^{-3}$ after the forming gas and $\mathrm{H}_{2}$ gas anneals where the absorption signal saturates. Si substitutes for $\mathrm{Ti}$ in rutile $\mathrm{TiO}_{2}{ }^{71,72}$ and is not expected to introduce localized electronic states in the bandgap but rather to give rise to bandgap narrowing. ${ }^{60,72} \mathrm{Li}$ in an interstitial configuration is potentially a shallow donor, ${ }^{26,60}$ but the predicted $E_{\mathrm{A}}$ value is only $30 \mathrm{meV}$ and does not agree with those of our three common levels. Also, the anticipated electron trap positions associated with $\mathrm{Cr}$ in rutile $\mathrm{TiO}_{2}$ deviate substantially from those of our three common levels, exhibiting values of $190 \mathrm{meV}$ and $410 \mathrm{meV}$ below the conduction band edge. ${ }^{46}$ Hence, both $\mathrm{Li}$ and $\mathrm{Cr}$ (as well as $\mathrm{Si}$ ) are ruled out as likely candidates for the three common levels while $\mathrm{Al}$ in combination with $\mathrm{V}_{\mathrm{O}}$ appears to be a more plausible suggestion. $\mathrm{Al}$ itself substitutes for $\mathrm{Ti}$ and gives rise to an acceptor level in the lower part of the bandgap, i.e., $\mathrm{Al}$ on the $\mathrm{Ti}$ site acts as a p-type dopant. ${ }^{34,73}$ However, on the basis of generation noise recombination and temperature-dependent Hall effect measurements, it is argued by different authors ${ }^{60,74}$ that Al-related shallow acceptor states also occur close to the conduction band. In particular, Acket and Volger ${ }^{60}$ have ascribed a level at $\sim 50 \mathrm{meV}$ below the conduction band edge to a $2 \mathrm{Al}_{\mathrm{Ti}}-\mathrm{V}_{\mathrm{O}}$ complex which may be associated with our most shallow "general" defect level $\left(E_{\mathrm{A}} \approx 70 \mathrm{meV}\right)$ or alternatively with the prominent one at $\approx 60 \mathrm{meV}$ detected after forming gas and $\mathrm{N}_{2}$ gas anneals only $\left(D_{2, \mathrm{FG}}, D_{2, \mathrm{~N}}\right)$.

Interstitial $\mathrm{H}$ is prevailing in all the studied samples, as manifested by its characteristic absorption line at $\sim 3290 \mathrm{~cm}^{-1}$ in the acquired IR spectra. This holds already for the as-received samples and becomes even more clear after the forming gas and $\mathrm{H}_{2}$ gas heat treatments. $\mathrm{H}_{\mathrm{i}}$ is a shallow donor in $\mathrm{TiO}_{2}$, and the $3290 \mathrm{~cm}^{-1}$ line originates from the local vibrational mode of an $\mathrm{O}-\mathrm{H}$ bond oriented perpendicular to the c-axis of the crystal. ${ }^{30,53}$ Monitoring the free carrier absorption as a function of temperature and concurrently the transformation between neutral and positively ionized $\mathrm{H}_{\mathrm{i}}$, Herklotz et al. ${ }^{30}$ determined $E_{\mathrm{A}}$ to be $10 \pm 1 \mathrm{meV}$ for the $\mathrm{H}_{\mathrm{i}}$ donor. This value is also corroborated by a muon spectroscopy study conducted by Shimomura et al. ${ }^{22}$ To the best of our knowledge, no corresponding theoretical estimates are available in the literature. Accordingly, $\mathrm{H}_{\mathrm{i}}$ can be excluded as the origin of any of the three "general" defect levels observed in the present samples. However, in addition to $\mathrm{Ti}_{\mathrm{i}}$ and possibly $\mathrm{V}_{\mathrm{O}}, \mathrm{H}_{\mathrm{i}}$ is an obvious candidate for the strong shallow donor activity found in our samples, exhibiting limited carrier freeze-out even at $28 \mathrm{~K}$. That is, the dominant donor(s) must have an ionization energy below $\sim 25 \mathrm{meV}$. Such very shallow donor states in reduced rutile $\mathrm{TiO}_{2}$ have also been reported by other authors, ${ }^{9-13}$ and they are, indeed, expected to be due to intrinsic defect defects (like $\mathrm{Ti}_{\mathrm{i}}$ and possibly $\mathrm{V}_{\mathrm{O}}$ ) and/or common residual impurities (like $\mathrm{H}_{\mathrm{i}}$ ). Here, it should also be noted that the abnormal decrease in the depletion capacitance observed at temperatures above $50-100 \mathrm{~K}$ in the TAS measurements (Fig. 3) is not caused by a decreasing concentration of ionized shallow donors but primarily attributed to the temperature variation of $\epsilon_{\mathrm{r}}$ in rutile $\mathrm{TiO}_{2}{ }^{55}$

Finally, as demonstrated in Fig. 5, no common deeplevel defect $\left(E_{\mathrm{A}} \geq 200 \mathrm{meV}\right)$ is found to be present in different samples. A rather prominent level with $E_{\mathrm{A}} \approx 300 \mathrm{meV}$ exists after $\mathrm{N}_{2}$ gas annealing $\left(E_{5, \mathrm{~N}}\right)$ but not after forming gas and $\mathrm{H}_{2}$ gas annealing. The opposite holds for the pronounced level with $E_{\mathrm{A}} \approx 460 \mathrm{meV}\left(E_{7, \mathrm{FG}}\right.$ and $\left.E_{5, \mathrm{H} 2}\right)$, present after forming gas and $\mathrm{H}_{2}$ gas annealing but not after $\mathrm{N}_{2}$ gas annealing. This indicates that these levels arise from (i) defects involving residual impurities with varying concentrations in different samples and/or (ii) complexes involving intrinsic defects being strongly influenced by the annealing conditions used. Further work needs to be pursued in order to resolve this issue.

\section{SUMMARY}

The DLTS and TAS techniques are demonstrated to be highly applicable for detailed investigations of electrically active defects in rutile $\mathrm{TiO}_{2}$ single crystals. A comprehensive study of $\mathrm{Pd} / \mathrm{TiO}_{2} / \mathrm{InGa}$ junctions has been performed using $\mathrm{TiO}_{2}$ crystals post-growth heat-treated in $\mathrm{FG}, \mathrm{H}_{2}$, or $\mathrm{N}_{2}$ atmospheres. Irrespective of the sample production batch and the heat-treatment employed, three rather shallow levels occur in all the samples with $E_{\mathrm{A}} \approx 70 \mathrm{meV}, \approx 95 \mathrm{meV}$ and $\approx 120 \mathrm{meV}$, respectively. The origins of these levels are discussed in some detail where electron polarons and intrinsic defects such as $\mathrm{Ti}_{i}$ and $\mathrm{V}_{\mathrm{O}}$ appear as viable candidates and complexes involving common residual impurities, especially $\mathrm{Al}$ in combination with $\mathrm{V}_{\mathrm{O}}$. Furthermore, TAS data display limited charge carrier freeze-out even at $28 \mathrm{~K}$ (minimum temperature reached) and evidence the presence of dominant and very shallow donors $\left(E_{\mathrm{A}} \leq 25 \mathrm{meV}\right)$. An obvious shallow donor is the omnipresent $\mathrm{H}_{\mathrm{i}}$, as revealed by infrared absorption measurements of the studied samples, having an ionization energy of only $\sim 10 \mathrm{meV}$. In contrast to the shallow defects, no common deep-level defect is found to be 
present in different samples, possibly indicating a stronger dependence on the annealing conditions used.

\section{ACKNOWLEDGMENTS}

Financial support by the Faculty of Mathematics and Natural Sciences at the University of Oslo via the strategic research initiative FOXHOUND and the Research Council of Norway via the EEA-JRP-RO-NO-2013-1 European Project (PERPHECT) is gratefully acknowledged. Experimental support by the Norwegian Micro- and Nanofabrication facility (NorFab) is highly appreciated.

${ }^{1}$ A. Fujishima and K. Honda, Nature 213, 8656 (1972).

${ }^{2}$ O. Carp, C. L. Huisman, and A. Reller, Prog. Solid State Chem. 32, 33 (2004).

${ }^{3}$ Y. Cong, J. Zhang, F. Chen, and M. Anpo, J. Phys. Chem. C 111, 6976 (2007).

${ }^{4}$ M. Grätzel, Inorg. Chem. 44, 6841 (2005).

${ }^{5}$ A. Kojima, K. Teshima, Y. Shirai, and T. Miyasaka, J. Am. Chem. Soc. 131, 6050 (2009)

${ }^{6}$ X. Pan, M.-Q. Yang, X. Fu, N. Zhang, and Y.-J. Xu, Nanoscale 5, 3601 (2013).

${ }^{7}$ A. Naldoni, M. Allieta, S. Santangelo, M. Marelli, F. Fabbri, S. Cappelli, C. L. Bianchi, R. Psaro, and V. Dal Santo, J. Am. Chem. Soc. 134, 7600 (2012).

${ }^{8}$ Z. Wang, C. Yang, T. Lin, H. Yin, P. Chen, D. Wan, F. Xu, F. Huang, J. Lin, X. Xie, and M. Jiang, Adv. Funct. Mater. 23, 5444 (2013).

${ }^{9}$ P. F. Chester and D. H. Bradhurst, Nature 199, 1056 (1963).

${ }^{10}$ R. G. Breckenridge and W. R. Hosler, Phys. Rev. 91, 793 (1953).

${ }^{11}$ J. W. Deford and O. W. Johnson, J. Appl. Phys. 54, 889 (1983).

${ }^{12}$ F. A. Grant, Rev. Mod. Phys. 31, 646 (1959).

${ }^{13}$ J. H. Becker and W. R. Hosler, Phys. Rev. 137, A1872 (1965).

${ }^{14}$ F. D. Brandão, M. V. B. Pinheiro, G. M. Ribeiro, and K. Krambrock, Phys. Rev. B 80, 235204 (2009).

${ }^{15}$ M. K. Nowotny, T. Bak, and J. Nowotny, J. Phys. Chem. B 110, 16270 (2006).

${ }^{16}$ M. K. Nowotny, L. R. Sheppard, T. Bak, and J. Nowotny, J. Phys. Chem. C 112, 5275 (2008).

${ }^{17}$ T. Bak, J. Nowotny, M. Rekas, and C. C. Sorrell, J. Phys. Chem. Solids 64, 1057 (2003).

${ }^{18}$ W. D. Ohlsen and O. W. Johnson, J. Appl. Phys. 44, 1927 (1973).

${ }^{19}$ P. Deák, B. Aradi, and T. Frauenheim, Phys. Rev. B 92, 045204 (2015).

${ }^{20}$ C. G. Van de Walle and J. Neugebauer, J. Appl. Phys. 95, 3851 (2004).

${ }^{21}$ R. Vilão, R. Vieira, H. Alberto, J. Gil, A. Weidinger, R. Lichti, B. Baker, P. Mengyan, and J. Lord, Phys. Rev. B 92, 081202 (2015).

${ }^{22}$ K. Shimomura, R. Kadono, A. Koda, K. Nishiyama, and M. Mihara, Phys. Rev. B 92, 075203 (2015).

${ }^{23}$ A. Janotti, C. Franchini, J. B. Varley, G. Kresse, and C. G. Van de Walle, Phys. Status Solidi - RRL 7, 199 (2013).

${ }^{24}$ P. Deák, B. Aradi, and T. Frauenheim, Phys. Rev. B 86, 195206 (2012).

${ }^{25}$ A. T. Brant, N. C. Giles, and L. E. Halliburton, J. Appl. Phys. 110, 53714 (2011).

${ }^{26}$ A. T. Brant, N. C. Giles, L. E. Halliburton, A. T. Brant, N. C. Giles, and L. E. Halliburton, J. Appl. Phys. 113, 053712 (2013).

${ }^{27}$ V. N. Bogomolov, Y. A. Firsov, E. K. Kudinov, and D. N. Mirlin, Phys. Status Solidi B 35, 555 (1969).

${ }^{28}$ V. N. Bogomolov and D. N. Mirlin, Phys. Status Solidi B 27, 443 (1968).

${ }^{29}$ A. Hupfer, L. Vines, E. V. Monakhov, B. G. Svensson, and F. Herklotz, Phys. Rev. B 96, 085203 (2017).

${ }^{30}$ F. Herklotz, E. V. Lavrov, and J. Weber, Phys. Rev. B 83, 235202 (2011).

${ }^{31}$ W. P. Chen, Y. Wang, and H. L. W. Chan, Appl. Phys. Lett. 92, 112907 (2008).

${ }^{32}$ L.-B. Mo, Y. Wang, Y. Bai, Q.-Y. Xiang, Q. Li, W.-Q. Yao, J.-O. Wang, K. Ibrahim, H.-H. Wang, C.-H. Wan et al., Sci. Rep. 5, 17634 (2015).

${ }^{33}$ D. C. Cronemeyer, Phys. Rev. 113, 1222 (1959).

${ }^{34}$ E. Yagi, R. Hasiguti, and M. Aono, Phys. Rev. B 54, 7945 (1996).
${ }^{35}$ C. N. Duckworth, A. W. Brinkman, and J. Woods, Phys. Status Solidi A 75, K99 (1983).

${ }^{36}$ K. Kobayashi, M. Takata, Y. Fujimura, and S. Okamoto, J. Appl. Phys. 60, 4191 (1986).

${ }^{37}$ G. Mattioli, P. Alippi, F. Filippone, R. Caminiti, and A. A. Bonapasta, J. Phys. Chem. C 114, 21694 (2010).

${ }^{38}$ G. Mattioli, F. Filippone, P. Alippi, and A. A. Bonapasta, Phys. Rev. B 78, 241201(R) (2008).

${ }^{39}$ H. Iddir, Ö. Serdar, P. Zapol, and N. D. Browning, Phys. Rev. B 75, 073203 (2007).

${ }^{40}$ J. He, R. K. Behera, M. W. Finnis, X. Li, E. C. Dickey, S. R. Phillpot, and S. B. Sinnott, Acta Mater. 55, 4325 (2007).

${ }^{41}$ D. L. Losee, J. Appl. Phys. 46, 2204 (1975).

${ }^{42}$ J. Pautrat, B. Katircioglu, N. Magnea, D. Bensahel, J. Pfister, and L. Revoil, Solid-State Electron. 23, 1159 (1980).

${ }^{43}$ D. V. Lang, J. Appl. Phys. 45, 3023 (1974).

${ }^{44}$ S. A. Rabie, Phys. Rev. B 14, 2569 (1976).

${ }^{45}$ R. R. Addiss, A. K. Ghosh, and F. G. Wakim, Appl. Phys. Lett. 12, 397 (1968).

${ }^{46}$ R. W. A. Hillhouse, "The optical and electrical properties of titanium dioxide," Ph.D. thesis (Durham University, 1981).

${ }^{47}$ M. B. Farah, J. Electrochem. Soc. 145, 3550 (1998).

${ }^{48}$ J. Bonkerud, C. Zimmermann, F. Herklotz, E. Monakhov, L. Vines, and B. G. Svensson, "Electrical Characteristics of Pd Schottky Diodes on Hydrogenated $\mathrm{TiO}_{2}$ " (unpublished).

${ }^{49}$ R. Schifano, E. V. Monakhov, U. Grossner, and B. G. Svensson, Appl. Phys. Lett. 91, 193507 (2007).

${ }^{50}$ B. G. Svensson, K. H. Rydén, and B. M. S. Lewerentz, J. Appl. Phys. 66, 1699 (1989).

${ }^{51}$ A. A. Istratov, O. F. Vyvenko, H. Hieslmair, and E. R. Weber, Meas. Sci. Technol. 9, 477 (1998).

${ }^{52}$ R. Schifano, E. V. Monakhov, B. G. Svensson, W. Mtangi, P. Janse van Rensburg, and F. D. Auret, Phys. B: Condens. Matter 404, 4344 (2009).

${ }^{53}$ O. W. Johnson, J. Deford, and J. W. Shaner, J. Appl. Phys. 44, 3008 (1973).

${ }^{54} \mathrm{P}$. Blood and J. W. Orton, The Electrical Characterization of Semiconductors: Majority Carriers and Electron States (Academic Press, 1992), Vol. 13

${ }^{55}$ R. A. Parker, Phys. Rev. 124, 1719 (1961).

${ }^{56}$ J. Li, F. Li, X. Zhu, D. Lin, Q. Li, W. Liu, and Z. Xu, J. Alloys Compd. 692, 375 (2017).

${ }^{57}$ K. J. Yang and C. Hu, IEEE Trans. Electron Devices 46, 1500 (1999).

${ }^{58}$ T. P. Weiss, A. Redinger, D. Regesch, M. Mousel, and S. Siebentritt, IEEE J. Photovoltaics 4, 1665 (2014).

${ }^{59}$ J. Pascual, J. Camassel, and H. Mathieu, Phys. Rev. B 18, 5606 (1978).

${ }^{60}$ G. Acket and J. Volger, Physica 32, 1680 (1966).

${ }^{61}$ H. P. R. Frederikse, J. Appl. Phys. 32, 2211 (1961).

${ }^{62}$ V. Cristea and V. Babeş, Phys. Status Solidi A 45, 617 (1978).

${ }^{63}$ W. R. Thurber and A. J. H. Mante, Phys. Rev. 139, A1655 (1965).

${ }^{64}$ J. F. Baumard and F. Gervais, Phys. Rev. B 15, 2316 (1977).

${ }^{65}$ S. Chakraborty, M. K. Bera, P. K. Bose, and C. K. Maiti, Semicond. Sci. Technol. 21, 335 (2006)

${ }^{66}$ L. A. Harris and R. Schumacher, J. Electrochem. Soc. 127, 1186 (1980).

${ }^{67}$ T. Minato, Y. Sainoo, Y. Kim, H. S. Kato, K.-i. Aika, M. Kawai, J. Zhao, H. Petek, T. Huang, W. He, and B. Wang, J. Chem. Phys. 130, 124502 (2009).

${ }^{68}$ G. I. Roberts and C. R. Crowell, J. Appl. Phys. 41, 1767 (1970).

${ }^{69}$ J. D. Wiley and G. L. Miller, IEEE Trans. Electron Devices 22, 265 (1975).

${ }^{70}$ A. Broniatowski, A. Blosse, P. C. Srivastava, and J. C. Bourgoin, J. Appl. Phys. 54, 2907 (1983).

${ }^{71}$ S. Yang, L. E. Halliburton, A. Manivannan, P. H. Bunton, and D. B. Baker, Appl. Phys. Lett. 94, 162114 (2009).

${ }^{72}$ K. Yang, Y. Dai, and B. Huang, Chem. Phys. Lett. 456, 71 (2008).

${ }^{73}$ J. Yahia, Phys. Rev. 130, 1711 (1963).

${ }^{74}$ R. Zijlstra, F. Leeuwerik, and T. Kleinpenning, Phys. Lett. 23, 185 (1966). 